\title{
Design of a Sustainable Residential Microgrid System with DC and AC Buses Including PHEV and Energy Storage Device
}

\author{
L. Roggia ${ }^{1,2}$, L. Schuch ${ }^{1}$, C. Rech ${ }^{1}$, H. L. Hey ${ }^{1}$, and J. R. Pinheiro ${ }^{1}$ \\ ${ }^{1}$ Power Electronics and Control Research Group \\ GEPOC, DPEE, PPGEE, Federal University of Santa Maria \\ Av. Roraima 1000, Santa Maria, RS (Brazil) \\ Phone/Fax number: +55 5532208463 \\ e-mail: roggia@gmail.com, schuch.prof@gmail.com, rech.cassiano@gmail.com, renes@ctlab.ufsm.br \\ ${ }^{2}$ Federal Institute of Rio Grande do Sul \\ Rua Nelsi Ribas Fritsch, 1111, Ibirubá, RS (Brazil) \\ Phone/Fax number: +55 5433248100
}

\begin{abstract}
A sustainable residential microgrid composed of two distributed generation sources (photovoltaic panels and biofuel generator), one energy storage device (battery bank), and able of supplying both AC and DC loads, including a plug-in hybrid electric vehicle, is proposed. The microgrid can operate in grid-connected mode and island mode. It is composed of a main DC bus and also an AC bus. The characteristics of the system, the operation modes description and some results are presented in this paper.
\end{abstract}

\section{Key words}

Microgrid, distributed generation, renewable energy, sustainable house.

\section{Introduction}

Electrical energy consumption has been considerably increasing in recent years. The population growth has direct influence towards this fact. Therefore, it is essential to increase the electric power generation. Besides, once fossil fuels (the actual dominant energy production source) produce enormous amount of pollution and are becoming scarce, other sources for electric power generation, mainly clean and renewable ones, have been receiving more attention and importance lately. Among these renewable sources, the most studied are wind, solar, biomass, and fuel cells.

Distributed generation (DG) technologies have been gaining interest due to benefits, such as: high reliability and high power quality, along with the fact that they are environmental friendly. Moreover, the next benefits are also associated to DG [1]: modularity, efficiency, reduced or absent emissions, security and load management. However, the uncontrolled use of individual DG units can cause various problems compromising their benefits [2]. Difficulties to connect these units directly to the bulky AC system due to their variable and intermittent power generation, voltage oscillation in the line to which the sources are connected and protection issues are some of these problems.

A better way to apply the benefits and potential of DG is through the system approach in which the generation units and loads are associated in a way that they are seen and analyzed as a subsystem or microgrid. This approach has been gaining big notoriety recently. The microgrid or smart grid comprise a group of loads, renewable energy sources and energy storage devices operating as a single controllable system, capable of supplying energy to a local area [1]. They are also formed by a bus to which the elements are connected through static power converters, which are generally arranged in parallel connections. One of the most important advantages of the microgrid is the fact that the energy sources and the entire system increase the reliability of energy supply to the connected loads [3]. This occurs due to the presence of various generation sources and also energy storage elements.

Regarding the connection methods of the distributed energy sources, energy storage devices and different types of loads in a microgrid, basically three alternatives can be adopted, which are: interconnection DC bus, interconnection AC bus or interconnection high frequency AC bus. The DC bus is the most simple and common interconnection bus. This system has no frequency and phase control requirements, high efficiency and high reliability compared to the AC interconnection bus [4]. Moreover, it has low distribution and transmission losses, low cost, possibility to operate in long distances and dispenses the use of transformers, leading to volume and cost reduction [1].

Small scale microgrid residential systems have been studied [5]-[9], and some of them include the possibility 
to connect plug-in hybrid electric vehicles (PHEV). The development of PHEVs occurred with the main objectives to reduce the fossil fuel and to increase the vehicles autonomy. The integration of PHEVs in microgrid systems is useful, once generally the vehicles have their batteries charged connected to their owners residences. Moreover, it is an interesting, logic and viable alternative to use non polluting energy sources to supply less polluting vehicles. It is important to highlight that the PHEV can also be used as a power source to supply energy to the microgrid if desired.

Therefore, this work is focused on the study and design of a residential microgrid system with a main DC bus composed of renewable energy sources, energy storage device, typical residential loads and PHEV load. The microgrid has also an AC bus. It is able to drain or inject power in the utility grid. Special attention is concentrated on the design of the system (configuration, converters and buses), operation modes and control of each static power converter connected to the microgrid.

It is important to highlight that when several converters are connected to a main bus, some problems can arise in the system. One of these problems regards the emergence of ripples and variations in the bus voltage waveform, once the various converters can interact in a manner that they impair the voltage regulation. Another problem refers to the incorrect power (load) sharing among the converters, once one of them can drain or supply more current than the desired, which can be unfavorable depending on the operation mode and system conditions.

The most critical situations generally occur under disturbances, such as: connection and disconnection of loads, variation of the instantaneous power generated by the DG sources, and fault or reconnection of the main grid. The solution to these problems consists in to define which converter(s) will take in or take off the current and, at the same time, do not allow the bus voltage to overly raise or fall, surpassing tolerance boundaries that guarantee the correct operation of the entire system.

Therefore, one strategy to define which converters operate under distinct situations, their specifications and control methods (for instance, current or voltage mode) in the residential microgrid is under study and will generate content for next publications. The strategy should be based in variables like energy generation cost, global system efficiency, life cycle deterioration of the main elements, dynamic performance, among others.

As an example, the instantaneous connection of high power loads in the system or the sudden power generation fall of a particular DG source in islanded mode, can cause DC bus voltage level reduction under the peak AC voltage waveform. This results in deformations at the waveform peaks and valleys, and deteriorates the power quality.

\section{Residential Microgrid System}

This section presents the residential microgrid system under study. The next subsections describe the system
(DG sources, storage devices, types of load and types of buses), operation modes (including the operation flowchart), converters topology, converters specifications and bus voltages levels.

\section{A. System Design}

The proposed residential microgrid is composed of two DG sources (photovoltaic panels and biofuel generator) and one battery bank, and is able of supplying both AC and DC loads, including a PHEV. The microgrid has two buses: one main DC bus in which the DG sources, storage device and DC loads are connected, and one AC bus in which AC loads are connected and the point of common coupling (PCC) with the utility grid is located. Figure 1 illustrates the microgrid system. The arrows beside each converter indicate the possible power flow directions.

\section{B. Operation Modes}

This subsection presents considerations to define the system operation modes and operation flowchart. This is a very important stage, because it describes in which manner the microgrid will operate in each possible situation, depending on some input variables. It is important to highlight that the microgrid can operate in both grid connected and island modes. The considerations are listed next.

1) The photovoltaic (PV) panels rated power is lower than the microgrid total installed load.

2) The generator presents a starting time until begin the energy generation.

3) The battery bank can be charged through the main grid or photovoltaic panels.

4) The battery bank only discharges to supply loads or to maintain the buses voltages, never to export energy to the main grid.

5) In grid connected mode, the battery bank is always fully charged or being charged.

Figure 2 illustrates the microgrid operation flowchart.

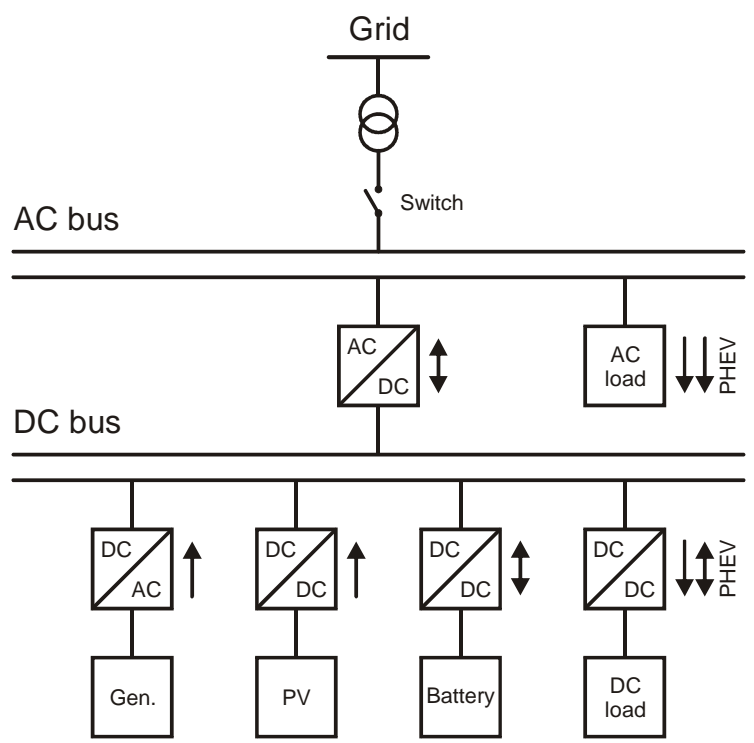

Figure 1. Residential microgrid system under study. 


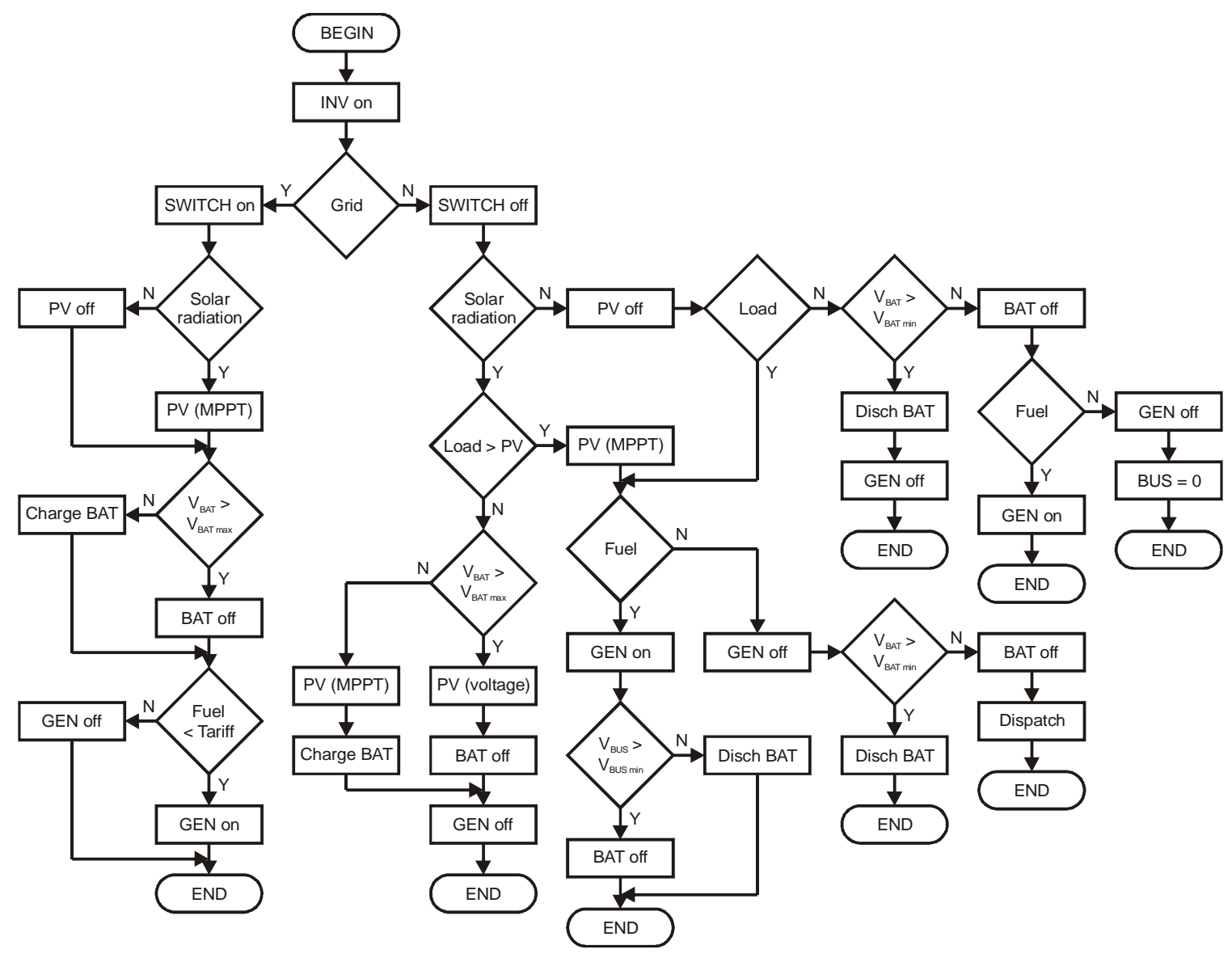

Figure 2. Microgrid operation flowchart.

The battery bank converter has three operation modes: battery charge, battery discharge supplying the required power, or battery discharge to supplying the required power and simultaneously regulating the DC bus voltage. The PV panels converter has two operation modes: MPPT control (perturbation and observation method) or voltage mode (DC bus voltage regulation). The inverter/rectifier converter has two operation modes: it controls the DC bus voltage and the AC sinusoidal current in grid connected mode, and it controls the sinusoidal AC voltage in island mode. The biofuel generator converter has two operation modes: current mode or voltage mode (DC bus voltage regulation).

\section{Converters Power Levels and Buses Voltages}

The residential load is equal to $12 \mathrm{~kW}$, once this value corresponds to a middle class house. The Toyota Prius Plug-in vehicle was chosen as PHEV. It has a total battery energy equal to $3.56 \mathrm{kWh}$ and charging power near to 2.5 $\mathrm{kW}[10]$.

Therefore, the microgrid total load specification is equal to $14.5 \mathrm{~kW}$. Due to this fact, and according to local standard specifications, the system should have a single phase configuration.

The battery bank power rating is defined to supply basic elements of the residence (lighting, alarm system and electronic garage gate) totalizing $500 \mathrm{~W}$. This choice is made because the battery use if for emergency purpose, when the other sources are not available, increasing its life time. This way, the use of an expensive and bulky battery bank is incoherent.

The biofuel generator power is rated to supply all residential loads excluding electric shower and air conditioning system (resulting in $4.4 \mathrm{~kW}$ ). These are the highest power equipments and have individual disruption systems, making easy to interrupt the power flow to these equipments in island mode. If these two equipments were included, the generator rated power would be high and just a few times demanded, leading to high costs and idleness.

The PV panels generated energy is specified through the energy required to charge the PHEV twice a day. Considering the solar radiation equal to $3.86 \mathrm{kWh} / \mathrm{m}^{2}$, the photovoltaic panels power is $2.34 \mathrm{kWp}(18 \times 130 \mathrm{Wp}$ panels). Therefore, the electrical energy consumed by the $\mathrm{PHEV}$ is generated in a clean manner by the PV panels. It is important to notice that the energy transfer can occur directly or through the main electric grid. In other words, during the day the excess energy is sold to the main grid and when desired to charge the vehicle the energy can be absorbed from the main grid, in a manner that the net energy flow is approximately equal to zero.

The AC bus voltage is defined as $220 \mathrm{~V}$, once most loads connected to this bus are supplied by $220 \mathrm{~V}$ and it coincides with the AC grid voltage. The DC bus voltage is defined as $400 \mathrm{~V}$, once this value allows the conversion to 
the AC bus through the inverter with an appropriate tolerance voltage margin.

\section{Converters Topologies}

The converter used to connect the energy storage device to the DC link presents a wide range of possibilities, according to a bibliographic review. As an example, in [11], the interleaved half-bridge converter is used. In [12], the traditional half-bridge converter is used. Some papers, like [13]-[15] present a comparison among several topologies, in order to highlight their advantages and limitations. Regarding these analysis, the half-bridge converter is chosen to connect the battery bank to the DC bus, due to advantages like requirement of only one inductor, lower current and voltage semiconductor stress levels, and higher efficiency in consequence of lower switching and conduction semiconductor losses and lower inductor losses. A detailed analysis on the energy storage system converter focusing the proposed residential microgrid in under analysis and will generate content for next publications.

A single phase unidirectional rectifier is used to connect the biofuel generator to the DC link due to its simplicity.

A boost converter is used to connect the PV panels to the DC link due to its simplicity, high efficiency and possibility of voltage boost required to this situation.

Finally, a single phase full-bridge inverter/rectifier is used to connect the DC bus to the AC bus. It is rated to the total DGs and battery bank power, resulting in $7.24 \mathrm{~kW}$.

\section{Results}

This section presents some simulation results. The control system operates using master-slave control method, in which only one converter controls each bus voltage at a time, while the other(s) operate in current mode. The system passive components are presented in table 1 .

Table I. Passive Components.

\begin{tabular}{l|c|c}
\hline \multicolumn{1}{c|}{ Component } & Symbol & Value \\
\hline PV boost converter inductor & $L_{p v}$ & $2.159 \mathrm{mH}$ \\
\hline PV output capacitor & $C_{p v}$ & $10 \mathrm{uF}$ \\
\hline Battery inductor & $L_{b a t}$ & $253.44 \mathrm{uH}$ \\
\hline Battery filter inductor & $L_{f b a t}$ & $1.69 \mathrm{uH}$ \\
\hline Battery filter capacitor & $C_{f b a t}$ & $1 \mathrm{mF}$ \\
\hline Battery voltage & $V_{b a t}$ & $48 \mathrm{~V}$ \\
\hline Inverter inductor & $L_{i n v}$ & $3.324 \mathrm{mH}$ \\
\hline DC link capacitor & $C_{d c}$ & $2 \mathrm{mF}$ \\
\hline
\end{tabular}

Figure 3 shows the simulation when DC load is connected to the microgrid, in grid-connected mode. Initially, the PV panels operate in MPPT mode and the produced power $(2340 \mathrm{~W})$ is entirely injected in the main grid through the inverter. At $1 \mathrm{~s}$, DC load $(1000 \mathrm{~W})$ is connected to the microgrid. The current through the inverter decreases from $10.64 \mathrm{~A}(2340 \mathrm{~W})$ to $6.09 \mathrm{~A}(1340 \mathrm{~W})$, once part of the current is directed to supply the DC load. Therefore, the current through the DC load increases from 0 A to 2.5 A. The DC bus voltage returns to the default value, regulated by the inverter/rectifier, which has two control loops using proportional-integral (PI) controllers, one to regulate the DC voltage and another to control the AC current.

Figure 4 shows the simulation results of the situation when the power produced from the PV panels decrease instantly to $0 \mathrm{~W}$ (worst case scenario). Initially, the PV panels are supplying power to DC loads (800 W) at MPPT with half sun maximum radiation $(1170 \mathrm{~W})$ and injecting the surplus power $(370 \mathrm{~W})$ to the main grid through the inverter. At $1 \mathrm{~s}$, the PV panels produced power decreases to $0 \mathrm{~W}$ and the main grid instantly starts to supply the DC loads. The current through the inverter increases from $1.68 \mathrm{~A}(370 \mathrm{~W})$ to $3.64 \mathrm{~A}(800 \mathrm{~W})$ and there is a $180^{\circ}$ phase change, indicating the inversion in the power flow direction. The DC bus voltage returns to the default value, regulated by the inverter/rectifier.

Figure 5 shows the simulation results of the situation when the microgrid changes from grid connected mode to island mode, due to a fault in the main grid power supply. Initially, the PV panels are supplying power to AC loads (1000 W) at MPPT with sun maximum radiation (2340 W) through the inverter and injecting the surplus power $(1340 \mathrm{~W})$ to the main grid also through the inverter.

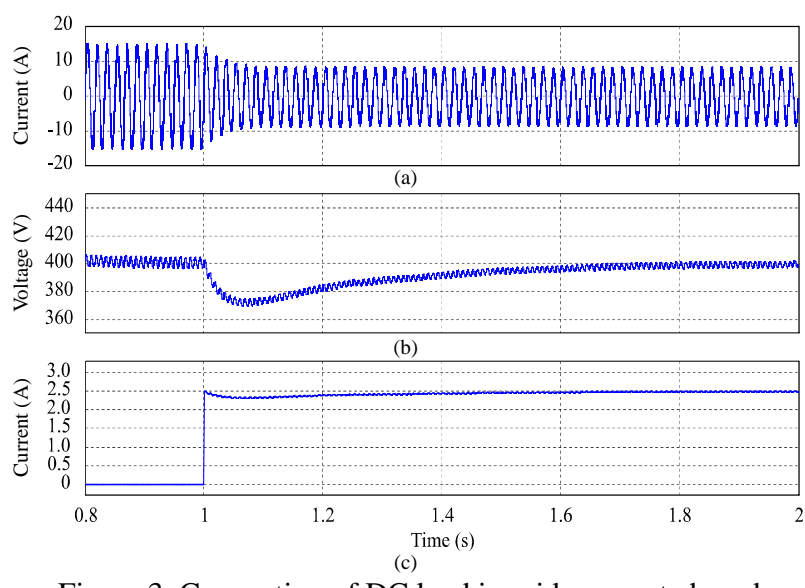

Figure 3. Connection of DC load in grid-connected mode.

(a) Inverter current. (b) DC bus voltage. (c) DC load current.
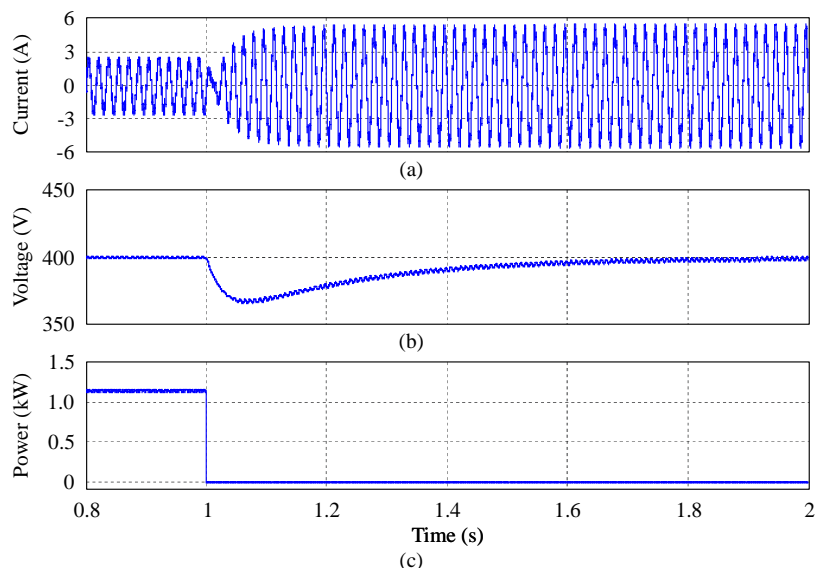

Figure 4. PV panels power generation decrease from $1170 \mathrm{~W}$ to 0 W. (a) Inverter current. (b) DC bus voltage. (c) PV panels power. 
At $1 \mathrm{~s}$, there is a fault in the main grid. Therefore, the PV panels converter changes from the MPPT mode to voltage mode (using a PI controller), in order to maintain the DC bus voltage in $400 \mathrm{~V}$ and to generate only the instantaneous required power $(1000 \mathrm{~W})$. The inverter also changes the operation mode, transferring from DC bus voltage regulation to AC bus voltage control (also applying a PI controller). The current through the inverter decreases from $10.64 \mathrm{~A}(2340 \mathrm{~W})$ to $4.55 \mathrm{~A}(1000 \mathrm{~W})$ and there is no phase inversion, indicating that the power flow direction is not modified. The DC bus voltage returns to the default value, regulated by the PV panels converter.

\section{Conclusion}

A sustainable single phase residential microgrid composed of two DG sources, one energy storage device, and able of supplying both AC and DC loads, including a PHEV (which can also operate as power source), is proposed. The microgrid has a main DC bus and can operate in gridconnected mode, as well as in island mode. In gridconnected mode, the microgrid is able to drain or inject power in the main grid depending on the generated power and connected load. Design of the system, including converters rated powers and topologies, along with the operation modes and operation microgrid flowchart are presented. Results prove the effectiveness of the microgrid control system.

\section{Acknowledgement}

The authors would like to thank CAPES (Coordenação de Aperfeiçoamento de Pessoal de Nível Superior) for the financial support.

\section{References}

[1] F. A. Farret and M. G. Simões, Integration of alternative sources of energy, John Wiley \& Sons, New Jersey (2006), pp. 471.

[2] R. H. Lasseter and P. Paigi, "Microgrid: a conceptual solution", in Proceedings IEEE Power Electronics Specialists Conference, 2004, vol. 6, pp. 4285-4290.

[3] A. Kwasinski and P. T. Krein, "Multiple-input DC-DC converters to enhance local availability in grids using distributed generation resources”, in Proceedings IEEE Applied Power Electronics Conference, 2007, pp. 16571663.

[4] J. Chen, J. Chen, R. Chen, X. Zhang, and C. Gong, "Decoupling control of the non-grid-connected wind power system with the droop strategy based on a DC micro-grid”, in Proceedings of World Non-Grid-Connected Wind Power and Energy Conference, 2009, pp. 1-6.

[5] P.-W. Lee, Y.-Z. Lee, and B.-T. Lin, "Power distribution systems for future homes", in Proceedings IEEE International Conference on Power Electronics and Drive Systems, vol. 2, 1999, pp. 1140-1146.

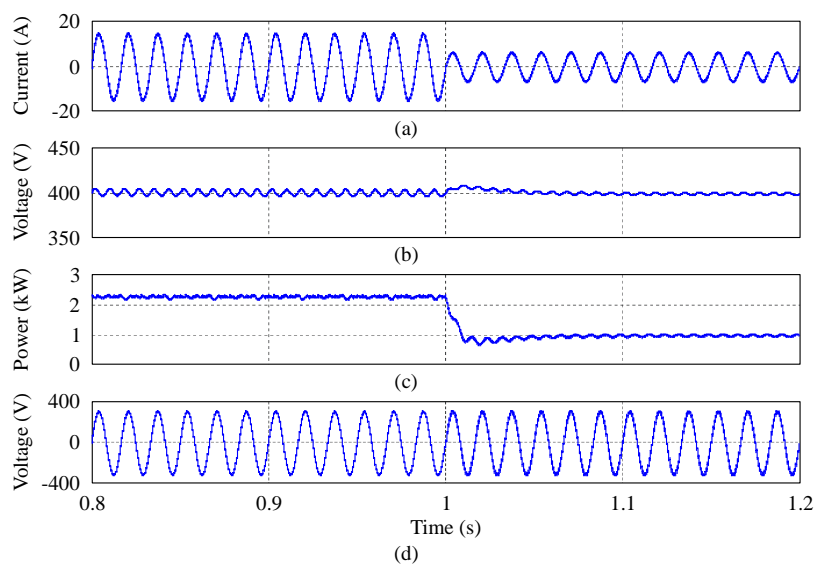

Figure 5. Change from grid-connected to island mode.

(a) Inverter current. (b) DC bus voltage. (c) PV panels power.

(d) AC bus voltage.

[6] H. Kakigano, Y. Miura, and T. Ise, "Configuration and control of a DC microgrid for residential houses", in Proceedings of Transmission \& Distribution Conference \& Exposition: Asia and Pacific, 2009, pp. 1-4.

[7] H. Kakigano, Y. Miura, and T. Ise, "Fundamental characteristics of DC microgrid for residential houses with cogeneration system in each house”, in Proceedings IEEE Power and Energy Society General Meeting, 2008, pp. 1-6.

[8] Y. Gurkaynak, Z. Li, and A. Khaligh, "A novel grid-tied, solar powered residential home with plug-in hybrid electric vehicle (PHEV) loads", in Proceedings IEEE Vehicle Power and Propulsion Conference, 2009, pp. 813-816.

[9] K. Clement-Nyns, E. Haesen, and J. Driesen, "The impact of charging plug-in hybrid electric vehicles on a residential distribution grid", in IEEE Transactions on Power Systems, vol. 25, no. 1, pp. 371-380, Feb. 2010.

[10] http://priuschat.com/news/toyota-officially-introducesprius-plug-in-phv-hybrid.

[11] J. Lee, B. Han, and H. Cha, "Operational analysis of DC micro-grid using detailed model of distributed generation", in Proceedings of Transmission \& Distribution Conference \& Exposition: Asia and Pacific, 2009, pp. 1-4.

[12] H. Kakigano, Y. Miura, T. Ise, and R. Uchida, "DC microgrid for super high quality distribution - system configuration and control of distributed generations and energy storage devices”, in Proceedings IEEE Power Electronics Specialists Conference, 2006, pp. 1-7.

[13] Y. Du, X. Zhou, S. Bai, S. Lukic, and A. Huang, "Review of non-isolated bi-directional DC-DC converters for plugin hybrid electric vehicle charge station application at municipal parking decks”, in Proceedings IEEE Applied Power Electronics Conference and Exposition, 2010, pp. 1145-1151.

[14] R. M. Schupbach and J. C. Balda, "Comparing DC-DC converters for power management in hybrid electric vehicles", in Proceedings IEEE International Electric Machines and Drives Conference, vol. 3, 2003, pp. 13691374.

[15] D. C. Erb, O. C. Onar, and A. Khaligh, "Bi-directional charging topologies for plug-in hybrid electric vehicles”, in Proceedings IEEE Applied Power Electronics Conference and Exposition, 2010, pp. 2066-2072. 